\title{
Prolonged air leak following lung resection - does Tri-staplerTM technology improve the incidence?
}

\author{
V Srivastava, M Mydin", T Smailes, J Cotts, J Dunning \\ From World Society of Cardiothoracic Surgeons 25th Anniversary Congress, Edinburgh \\ Edinburgh, UK. 19-22 September 2015
}

\section{Background/Introduction}

Prolonged air leak following lung resection leads to delayed discharge and increases risk of infection. The incidence of prolonged air leak (defined as greater than 7 days) is approx. 9\% in the U.K. (SCTS Cardiothoracic Surgery database 2011). The Covidien Tri-staplerTM technology (Covidien, Mansfield, MA) claims to improve air leak rates following lung resection through improved vascularity at the suture line. We started using these staplers in August 2012.

\section{Aims/Objectives}

To determine if Covidien Tri-staplersTM improve prolonged air leak incidence through comparison with the incidence in previous two years (i.e. August 2010 - July 2012).

\section{Method}

The departmental database which collects and validates data prospectively was used to find patients having nonpneumothorax lung resection surgery between August 2010 and July 2014. They were divided into two groups Group 1 (EndoGIA Autosuture ${ }^{\mathrm{TM}}$; August 2010 - July 2012) and Group 2 (Tri-stapler ${ }^{\mathrm{TM}}$ device; August 2012 August 2014). The groups were then compared for preoperative variables and postoperative outcomes.

\section{Results}

A total of 401 patients were included - Group 1 with 242 patients (102 males - 42.1\%) and Group 2 with 159 patients (72 males - 45.3\%). Mean age was 67.5 years (Group1) and 67.6 years (Group2); $\mathrm{p}=0.92$. COPD incidence was $59(24.4 \%)$ patients in Group 1 and 66 (41.5\%) patients in Group 2; $\mathrm{p}<0.001$. There was no significant differences in the incidence of prolonged air leak in Group $1(\mathrm{n}=20 ; 8,3 \%)$ and Group $2(13 ; 8.2 \%) ; \mathrm{p}=0.98$.

Dept of Cardiothoracic Surgery, James Cook University Hospital, Middlesbrough, UK 